\title{
Multistep synthesis of a valsartan precursor in continuous flow
}

\author{
Katharina Hiebler ${ }^{1} \cdot$ Sebastian Soritz ${ }^{1} \cdot$ Kristian Gavric $^{1} \cdot$ Sam Birrer $^{1} \cdot$ Manuel C. Maier $^{1} \cdot$ Bianca Grabner $^{1}$. \\ Heidrun Gruber-Woelfler ${ }^{1}$
}

Received: 3 June 2019 / Accepted: 12 July 2019 / Published online: 31 July 2019

(C) The Author(s) 2019

\begin{abstract}
Valsartan is a potent, orally active angiotensin II receptor blocker and is widely used in the treatment of hypertension and chronic heart failure. Herein, we present an approach for the continuous synthesis of a late-stage precursor of valsartan in three steps. The applied synthetic route involves $N$-acylation, Suzuki-Miyaura cross-coupling and methyl ester hydrolysis. After optimization of the individual steps in batch, they were successfully transferred to continuous flow processes employing different reactor designs. The first step of the synthetic route ( $N$-acylation) as well as the third step (methyl ester hydrolysis) are performed in coil reactor setups. The key step of the reaction cascade (Suzuki-Miyaura cross-coupling) is catalyzed by a heterogeneous palladiumsubstituted cerium-tin-oxide with the molecular formula $\mathrm{Ce}_{0.20} \mathrm{Sn}_{0.79} \mathrm{Pd}_{0.01} \mathrm{O}_{2-\delta}$. The catalyst particles are implemented in an in-house developed packed-bed reactor, which features an HPLC column as fixed-bed. The combination of the individual reaction modules facilitates the consecutive performance of the three reaction steps. Using the developed multistep continuous setup, the targeted valsartan precursor was obtained with up to $96 \%$ overall yield.
\end{abstract}

Keywords Heterogeneous catalysis $\cdot$ Multistep flow chemistry $\cdot$ Palladium $\cdot$ Valsartan

\section{Introduction}

According to the World Health Organization (WHO), in 2015 about $31 \%$ of deaths were ascribable to cardiovascular diseases, thus being the leading cause of death globally. Especially people suffering from high blood pressure belong to the risk group to develop cardiovascular complaints. Therefore, a number of different medications for the treatment of hypertension are available on the market $[1,2]$. One popular therapy for lowering the patients' blood pressure is the administration of the non-

\section{Article Highlights}

- Development of a three-step synthesis of an advanced valsartan precursor in continuous flow.

- Consecutive continuous performance of $N$-acylation, Suzuki-Miyaura coupling and methyl ester hydrolysis.

- Combination of coil reactors and a fixed-bed reactor for the continuous reaction setup.

Electronic supplementary material The online version of this article (https://doi.org/10.1007/s41981-019-00044-x) contains supplementary material, which is available to authorized users.

Heidrun Gruber-Woelfler

woelfler@tugraz.at

1 Institute of Process and Particle Engineering, Graz University of Technology, Inffeldgasse 13/III, 8010 Graz, Austria peptide angiotensin II receptor blocker valsartan $\mathbf{1}$. The active pharmaceutical ingredient (API) belongs to the class of sartans, which feature a biphenyl moiety as common structural unit. The biaryl scaffold plays a crucial role in the oral bioavailability as well as the binding of the API to the biological target $[3,4]$. Valsartan 1 was first introduced onto the market as Diovan $\AA$ by Novartis in $1997[5,6]$. In the course of ensuing years, several other combination preparations followed, such as Diovan HCT ${ }^{\circledR}$ (+hydrochlorothiazide, 1998), Exforge ${ }^{\circledR}$ (+amlodipine, 2007), Exforge HCT ${ }^{\circledR}$ (+amlodipine+hydrochlorothiazide, 2009), Valtura ${ }^{\circledR}$ (+aliskiren, 2009) and Entresto ${ }^{\circledR}$ (+sacubitril, 2015) $[7,8]$. Regarding the synthesis of the antihypertensive $\mathbf{1}$, it was first patented by Ciba-Geigy in 1991. The route involves the coupling of L-valine methyl ester $\mathbf{2}$ with biphenyl aldehyde 3a via reductive amination (Scheme 1). Subsequent acylation of the resulting intermediate $\mathbf{4}$ with valeryl chloride, triazole formation with an organotin reagent as well as saponification yielded the target molecule valsartan 1 [9].

However, the Ciba-Geigy route to $\mathbf{1}$ offered plenty of room for improvement. The use of a highly toxic tin reagent led to contamination of the final API and the process suffered from a poor overall yield of less than $10 \%$ [10]. Consequently, a substantial number of papers and patents focusing on novel synthesis strategies and optimization of the overall reaction process have been published [exemplarily 3, 11-20]. Alternative 


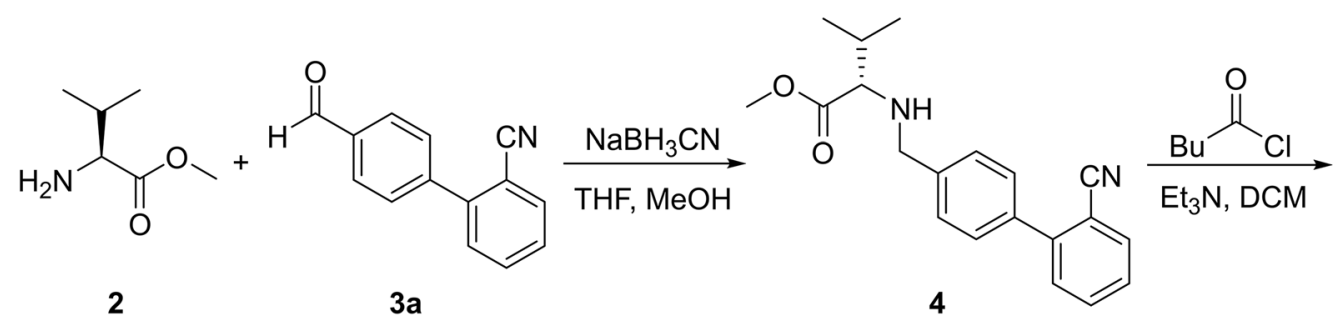<smiles>COC(=O)[C@H](C(C)C)N(Cc1ccc(-c2ccccc2C(C)(C)C)cc1)C(=O)Br</smiles>

5

Scheme 1 Patented Ciba-Geigy synthesis of valsartan [9]

approaches for the formation of valsartan $\mathbf{1}$ include Rucatalyzed C-H activation [17], Pd-catalyzed decarboxylative biaryl coupling [3], Zn-catalyzed Negishi reaction [18] and the use of trityl-protected tetrazole intermediates in the Pd-catalyzed Suzuki-Miyaura cross-coupling [14, 15]. Although differing considerably in terms of employed reagents, most strategies for the synthesis of valsartan $\mathbf{1}$ rely exclusively on traditional batch operations. Only very few papers deal with the synthesis of valsartan precursor compounds in continuous flow. Pandarus et al. reported the continuous Suzuki coupling of 2chlorobenzonitrile 7a with 4-methyl-phenylboronic acid 8 using a heterogeneous sol-gel entrapped SiliaCat DPP-Pd catalyst. Its implementation in a packed bed microreactor facilitated formation of valsartan building block $\mathbf{3 b}$ (Scheme 2, a). Nevertheless, Pandarus et al. observed rapid catalyst deactivation due to the instability of the active Pd-species towards dissolved oxygen in the presence of the aryl chloride substrate 7a [21]. Likewise, Nagaki and his group performed the continuous synthesis of valsartan intermediate 3a. First, organoboron species $\mathbf{9}$ is generated using a two-step tubular flow microreactor system. Then, Suzuki cross-coupling of the obtained intermediate with $\mathbf{1 0}$ is performed in a Pd-substituted monolithic microreactor (Scheme 2, b). Parallelization of five of these microreactor setups using a flow distributor allowed them to synthesize valsartan intermediate $\mathbf{3 a}$ on a larger scale with a productivity of $184 \mathrm{mg} \mathrm{h}^{-1}$ [22]. However, to the best of our knowledge, there are no approaches for the continuous multistep synthesis of an advanced valsartan precursor reported in literature. Therefore, the development of a multistep continuous setup for the synthesis of a late-stage valsartan precursor was the objective of our work.

In contrast to traditionally employed batch operations, flow reactors have a lot of benefits including improved energy efficiency, reduced waste generation and increased safety. Therefore, the Federal Drug Administration (FDA) aims for application of continuous synthesis in pharmaceutical manufacturing [23, 24]. Also, recent recalls of valsartan 1 generics, contaminated with carcinogenic $\mathrm{N}$ -
Scheme 2 Examples of continuous syntheses of valsartan building blocks $[21,22]$ (a)

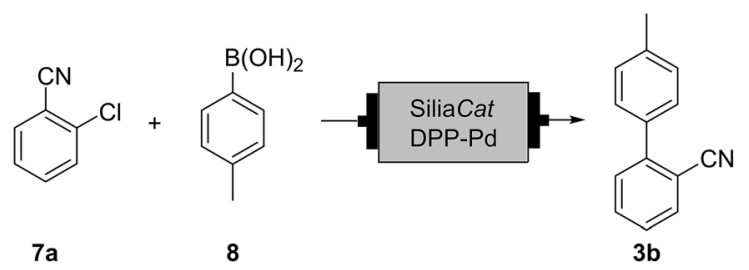

(b)

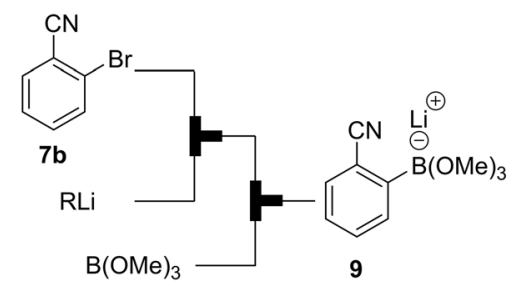


nitrosodimethylamine, highlight the need for alternative synthesis methods to obtain safe and pure APIs [25]. Therefore, within the framework of the ONE-FLOW research project [26], we targeted the integrated synthesis of valsartan precursor 13 in a continuous manner over three steps (Scheme 3). Firstly, $N$-acylation of boronic acid pinacol ester 11 with valeryl chloride yields the functionalized intermediate $\mathbf{1 2}$. Secondly, Suzuki-Miyaura cross-coupling of 12 with 2halobenzonitrile $\mathbf{7 b}$-c gives biphenyl compound $\mathbf{5}$. The key step of the reaction cascade is catalyzed by heterogeneous Pd$\mathrm{Ce}-\mathrm{Sn}$-oxides with the molecular formula $\mathrm{Ce}_{0.99-}$ ${ }_{x} \mathrm{Sn}_{\mathrm{x}} \mathrm{Pd}_{0.01} \mathrm{O}_{2-\delta}$ [27]. Thirdly, hydrolysis of the methyl ester group is achieved by aqueous base and yields the target compound 13. The valsartan precursor 13 can then be transformed to the targeted API 1 by the use of azides [28], but this transformation was not included in this work. However, it will be addressed in future approaches.

For the Suzuki-Miyaura cross-coupling, the use of in-house developed Pd-catalysts with the formula $\mathrm{Ce}_{0.99-\mathrm{x}} \mathrm{Sn}_{\mathrm{x}} \mathrm{Pd}_{0.01} \mathrm{O}_{2-\delta}$ is envisaged. Their applicability for cross-couplings of various ortho- and para-substituted bromoarenes with phenylboronic acid has already been reported by our group [27, 29]. The heterogeneous catalysts also proved to exhibit high functional group tolerance as well as minimal leaching behavior [27, 29]. Apart from that, the performance of continuous Suzuki crosscoupling reactions was successfully achieved by implementation of the catalysts in an in-house developed packed-bed reactor [30], referred to as Plug \& Play reactor. The customized reactor features exchangeable HPLC-columns filled with catalyst particles as well as modules for heating, cooling and mixing. Obtained results $[27,29,30]$ clearly indicate the high potential of the Pd-Ce-Sn-oxides for the synthesis of pharmaceutical and fine chemical intermediates in continuous flow and are promising in terms of the targeted synthesis of valsartan intermediate 13.

\section{Results and discussion}

\section{Optimization of the individual steps in batch}

In order to be able to design a continuous setup for the multistep synthesis of valsartan precursor 13, we first examined the three individual steps in batch. Since we wanted to keep the consumption of our intermediates $\mathbf{5 , 1 1}$ and $\mathbf{1 2}$ to a minimum and the optimization in flow would have required a higher amount of reagents (due to the equilibration times of our targeted continuous setups), we decided to identify a first set of suitable reaction parameters in batch. However, in view of the future improvement of the process, optimization will be performed in a continuous fashion in order to take the intrinsic dynamics and all other advantages of continuous systems into account. As the pivotal step of the reaction cascade is a Suzuki-Miyaura cross-coupling, we focused on step 2 in the beginning. For this transformation we had a number of heterogeneous Pd-catalysts in hand [27], which can readily be<smiles>[X]c1ccccc1C#N</smiles>

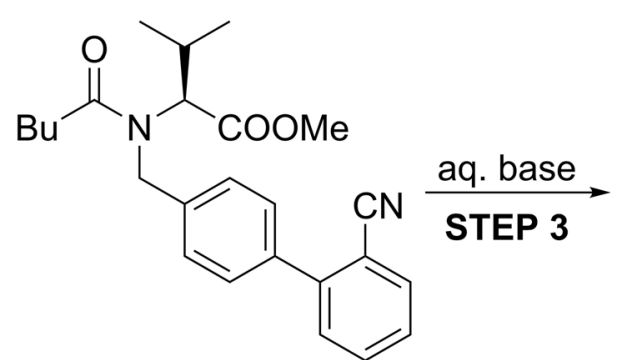

5

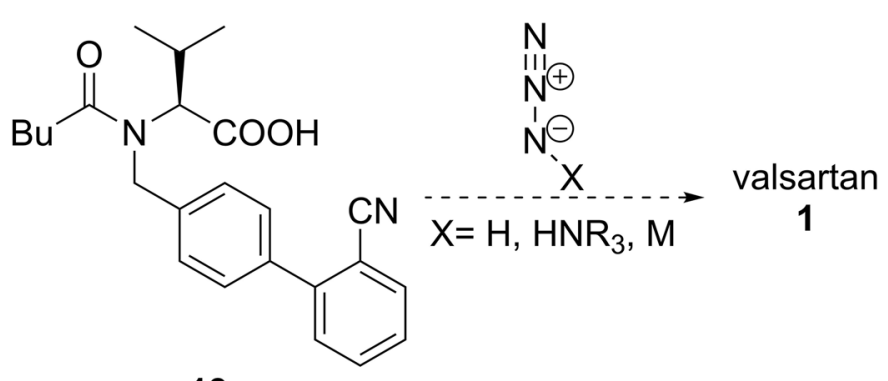

13

Scheme 3 Targeted three-step synthesis of valsartan precursor $\mathbf{1 3}$ in continuous flow (synthesis of $\mathbf{1}$ via tetrazole formation with organic azides is not included in this paper) 
implemented in a fixed-bed reactor for continuous flow applications [30]. Based on earlier studies, we chose to test three of them $\left(\mathrm{Ce}_{0.99-\mathrm{x}} \mathrm{Sn}_{\mathrm{x}} \mathrm{Pd}_{0.01} \mathrm{O}_{2-\delta}, \mathrm{x}=0.20,0.79,0.99\right)$ as they gave the best results in the Suzuki coupling of 2-bromobenzonitrile 7b with phenylboronic acid (standard reaction conditions: $1 \mathrm{~mol}$ eq. aryl halide, $1.5 \mathrm{~mol}$ eq. phenylboronic acid, 1.5 mol eq. $\mathrm{K}_{2} \mathrm{CO}_{3}$, EtOH: $\mathrm{H}_{2} \mathrm{O}=7: 3,75^{\circ} \mathrm{C}$ ) [27]. Our initial approaches for the synthesis of valsartan 1 involved the Suzuki coupling of boronic acid derivatives carrying a (trityl-protected) tetrazole or a nitrile group in ortho-position. These attempts failed due to deactivation of the employed Pdcatalyst and substrate degradation by rapid protolytic deboronation. However, we observed that boronic acid ester 12 couples smoothly with 2-halobenzonitrile 7b-c in EtOH: $\mathrm{H}_{2} \mathrm{O}=7: 3$ at $75^{\circ} \mathrm{C}$ (Scheme 3, step 2). In the employed aqueous reaction environment $\mathbf{1 2}$ is hydrolyzed to the free boronic acid, which is more reactive in Suzuki-Miyaura cross-couplings than its ester analogue [31]. Therefore, we chose to pursue a synthetic route involving the Suzuki coupling of 12 with $\mathbf{7 b}$-c leading to formation of valsartan precursor 13 as final product (Scheme 3). After having identified suitable cross-coupling partners, we wanted to determine the most active Pd-catalyst for our targeted transformation. Regarding the Suzuki coupling of 2-bromobenzonitrile $\mathbf{7 b}$ with boronic acid ester 12 using $1 \mathrm{~mol} \%$ of catalyst, the activity follows the order $\mathrm{Ce}_{0.20} \mathrm{Sn}_{0.79} \mathrm{Pd}_{0.01} \mathrm{O}_{2-\delta}>$ $\mathrm{Sn}_{0.99} \mathrm{Pd}_{0.01} \mathrm{O}_{2-\delta}>\mathrm{Ce}_{0.79} \mathrm{Sn}_{0.20} \mathrm{Pd}_{0.01} \mathrm{O}_{2-\delta}$ (Table 1, Entries $1-3)$. Hence, we decided to use $\mathrm{Ce}_{0.20} \mathrm{Sn}_{0.79} \mathrm{Pd}_{0.01} \mathrm{O}_{2-\delta}$ for all further experiments. Moreover, it is commonly known that the reactivity of aryl halides in Suzuki coupling increases along the halogen group $(\mathrm{Cl}<<\mathrm{Br}<\mathrm{I})$. As expected, a higher conversion was obtained when using 2-iodobenzonitrile 7c instead of $7 \mathbf{b}$ (Table 1, Entry 4). Consequently, 7c was the coupling partner of choice and the catalyst loading was decreased from $1 \mathrm{~mol} \%$ to $0.25 \mathrm{~mol} \%$ for further studies.
In view of the performance of a multistep reaction cascade and the realization of $N$-acylation prior to the Suzuki coupling, we next needed to identify a suitable solvent system for achieving both steps in a sequential fashion. As reported in literature [32] and experienced in our lab, water is crucial for the success of the Suzuki coupling using our class of catalysts. However, step 1 needs to be performed in an aprotic organic solvent to avoid hydrolysis of the valeryl chloride reagent. Since our chosen catalyst showed no or very low activity in two-phasic solvent systems (water + dicholoromethane/toluene/ethyl acetate), we needed a single liquid phase for the Suzuki coupling step. Highly polar water-miscible organic solvents (acetonitrile; $N, N$-dimethyl sulfoxide; $N, N$ dimethylformamide) did not prove to be compatible with our catalyst. However, considerable catalyst activity was detected in aqueous ethereal solvents (tetrahydrofuran (THF); 1,4-dioxane). As THF and water are not miscible in a 1:1 ratio at elevated temperatures [33], in this case the addition of an alcoholic solvent was further necessary to obtain one liquid phase. The choice of organic solvent also has a substantial influence on the leaching behavior of palladium, tin and cerium into the reaction solution. Our investigations in this respect showed that palladium leaching increases along with the polarity of the reaction solvent (Table 2). Highest levels of palladium were determined in ethanol-water $\left(3.12 \mathrm{mg} \mathrm{kg}^{-1}\right)$, whereas they were found to be lowest in dioxane-water $\left(0.37 \mathrm{mg} \mathrm{kg}^{-1}\right)$. Cerium leaching shows the exact opposite trend $\left(0.89 \mathrm{mg} \mathrm{kg}^{-1}\right.$ in ethanol-water, $2.53 \mathrm{mg} \mathrm{kg}^{-1}$ in dioxane-water, Table 2). In contrast, leaching of tin was found to be insignificant in all tested solvents $\left(0.06-0.08 \mathrm{mg} \mathrm{kg}^{-1}\right.$, Table 2). Due to the fact that minimal leaching of the active catalytic species palladium was targeted, we chose dioxanewater as the solvent for the Suzuki coupling step.

Regarding the optimal dioxane-to-water ratio for the Suzuki coupling step, solubility issues leave a narrow margin.

Table 1 Optimization of reaction conditions of step 2 in batch

\begin{tabular}{|c|c|c|c|c|c|c|c|}
\hline Entry & Solvent & $\begin{array}{l}\mathrm{T} \\
/{ }^{\circ} \mathrm{C}\end{array}$ & $\begin{array}{l}\text { Pd- } \\
\text { cat. }^{\text {a }}\end{array}$ & $\begin{array}{l}\text { Cat. loading } \\
/ \mathrm{mol} \%\end{array}$ & Aryl halide & Excess of $12 / \mathrm{mol}$ eq. & $\begin{array}{l}\text { Conversion } \\
/ \%\end{array}$ \\
\hline 1 & EtOH: $\mathrm{H}_{2} \mathrm{O}=7: 3$ & 75 & 1 & 1.00 & $7 \mathbf{b}$ & 1.10 & $10.0^{\mathrm{b}}$ \\
\hline 2 & EtOH: $\mathrm{H}_{2} \mathrm{O}=7: 3$ & 75 & 2 & 1.00 & $7 b$ & 1.10 & $60.1^{\mathrm{b}}$ \\
\hline 3 & EtOH: $\mathrm{H}_{2} \mathrm{O}=7: 3$ & 75 & 3 & 1.00 & $7 b$ & 1.10 & $47.3^{\mathrm{b}}$ \\
\hline 4 & EtOH: $\mathrm{H}_{2} \mathrm{O}=7: 3$ & 75 & 2 & 1.00 & $7 c$ & 1.10 & $95.3^{\mathrm{b}}$ \\
\hline 5 & Dioxane: $\mathrm{H}_{2} \mathrm{O}=65: 35$ & 80 & 2 & 0.25 & $7 c$ & 1.10 & $58.9^{\mathrm{c}}$ \\
\hline 6 & Dioxane: $\mathrm{H}_{2} \mathrm{O}=3: 2$ & 80 & 2 & 0.25 & $7 c$ & 1.10 & $83.6^{\mathrm{c}}$ \\
\hline 7 & Dioxane: $\mathrm{H}_{2} \mathrm{O}=1: 1$ & 80 & 2 & 0.25 & $7 \mathrm{c}$ & 1.10 & $88.6^{\mathrm{c}}$ \\
\hline 8 & Dioxane: $\mathrm{H}_{2} \mathrm{O}=1: 1$ & 80 & 2 & 0.25 & $7 \mathrm{c}$ & 1.25 & $92.2^{\mathrm{c}}$ \\
\hline 9 & Dioxane: $\mathrm{H}_{2} \mathrm{O}=1: 1$ & 80 & 2 & 0.25 & $7 \mathrm{c}$ & 1.50 & $95.0^{\mathrm{c}}$ \\
\hline
\end{tabular}

${ }^{\text {a }}$ Pd-catalyst 1: $\mathrm{Ce}_{0.79} \mathrm{Sn}_{0.20} \mathrm{Pd}_{0.01} \mathrm{O}_{2-\delta}$, Pd-catalyst 2: $\mathrm{Ce}_{0.20} \mathrm{Sn}_{0.79} \mathrm{Pd}_{0.01} \mathrm{O}_{2-\delta}$, Pd-catalyst 3: $\mathrm{Sn}_{0.99} \mathrm{Pd}_{0.01} \mathrm{O}_{2-\delta}$

${ }^{\mathrm{b}}$ Conversion of aryl halide $\mathbf{7 b}$-c after $15 \mathrm{~min}$ (determined by HPLC)

${ }^{\mathrm{c}}$ Conversion of aryl halide $\mathbf{7 b}$-c after 10 min (determined by HPLC) 
Table 2 Leaching of metals ( $\mathrm{Pd}, \mathrm{Sn}, \mathrm{Ce})$ into the reaction solution during step 2 using $\mathrm{Ce}_{0.20} \mathrm{Sn}_{0.79} \mathrm{Pd}_{0.01} \mathrm{O}_{2-\delta}(0.25$ mol\%) as catalyst and 2iodobenzonitrile $\mathbf{7 c}$ as aryl halide

\begin{tabular}{|c|c|c|c|c|c|c|}
\hline \multirow[t]{2}{*}{ Entry } & \multirow[t]{2}{*}{ Solvent } & \multirow{2}{*}{$\begin{array}{l}\mathrm{T} \\
/{ }^{\circ} \mathrm{C}\end{array}$} & \multirow{2}{*}{$\begin{array}{l}\text { Conversion }{ }^{\mathrm{a}} \\
/ \%\end{array}$} & \multicolumn{3}{|c|}{ Metal content ${ }^{\mathrm{b}} / \mathrm{mg} \mathrm{kg}^{-1}$} \\
\hline & & & & $\mathrm{Pd}$ & $\mathrm{Sn}$ & $\mathrm{Ce}$ \\
\hline 1 & Dioxane: $\mathrm{H}_{2} \mathrm{O}=1: 1$ & 85 & 97.9 & 0.37 & 0.08 & 2.53 \\
\hline 2 & Dioxane: $\mathrm{MeOH}: \mathrm{H}_{2} \mathrm{O}=1: 1: 1$ & 65 & 41.3 & 2.23 & 0.06 & 1.56 \\
\hline 3 & THF:MeOH: $\mathrm{H}_{2} \mathrm{O}=1: 1: 1$ & 65 & 33.5 & 1.90 & 0.06 & 1.29 \\
\hline 4 & EtOH: $\mathrm{H}_{2} \mathrm{O}=7: 3$ & 75 & 78.7 & 3.12 & 0.08 & 0.89 \\
\hline
\end{tabular}

${ }^{a}$ Conversion of 2-iodobenzonitrile $7 \mathbf{c}$ after 120 min (determined by HPLC)

${ }^{\mathrm{b}}$ Metal content determined by ICP-MS after acid-mediated digestion of the samples

If the reaction mixture is rich in water ( $\geq 55 \mathrm{v} \%$ ), employed organic compounds are not entirely soluble. If, on the other hand, dioxane is present in $\geq 70 \mathrm{v} \%$, the inorganic base potassium carbonate $\left(\mathrm{K}_{2} \mathrm{CO}_{3}\right)$ does not dissolve completely. An equivolume mixture of dioxane and water provided the best results for our reaction (Table 1, Entries 5-7). Apart from that, as expected the use of a larger excess of boronic acid ester $\mathbf{1 2}$ leads to an increased reaction rate (Table 1, Entries 8-9). Nevertheless, we decided to use 1.10 mol equivalents of $\mathbf{1 2}$ for the continuous reaction setup considering atom economy as well as by-product formation. Particularly, homocoupling and oxidation of the organoboron reagent were reported to occur upon depletion of the aryl halide coupling partner [27], causing a more complex reaction mixture.

After having identified optimum conditions in batch for the Suzuki coupling step, we concentrated our attention on step 1 of the reaction cascade (Scheme 3, step 1). $N$-acylation of 11, which was synthesized using a literature procedure [20], with valeryl chloride was performed in dioxane in presence of an organic base. We aimed for quantitative conversion of boronic acid ester $\mathbf{1 1}$ as previous experiments showed literature-known [34] deactivation of our Pd-catalyst, which is employed in the subsequent Suzuki coupling step, by N-H functional groups. We investigated the effect of temperature as well as molar equivalents of reagents (valeryl chloride, organic base) on the conversion (Table 3). $N, N$-diisopropylethylamine (DIPEA) was chosen

Table 3 Optimization of reaction conditions of step 1 in batch

\begin{tabular}{llllll}
\hline Entry & $\begin{array}{l}\mathrm{T} \\
/{ }^{\circ} \mathrm{C}\end{array}$ & $\begin{array}{l}\text { Mol eq. valeryl } \\
\text { chloride }\end{array}$ & $\begin{array}{l}\text { Mol eq. } \\
\text { DIPEA }\end{array}$ & $\begin{array}{l}\text { Conversion }^{\mathrm{a}} \mathrm{min} / \% \\
\mathrm{t}=1 \mathrm{~m}\end{array}$ & $\begin{array}{l}\text { Conversion }^{\mathrm{a}} \\
\mathrm{t}=5 \mathrm{~min} / \%\end{array}$ \\
\hline 1 & 40 & 1.05 & 1.05 & 20.0 & 59.0 \\
2 & 60 & 1.05 & 1.05 & 26.4 & 70.9 \\
3 & 80 & 1.05 & 1.05 & 36.7 & 84.7 \\
4 & 80 & 1.50 & 1.05 & 45.7 & 96.7 \\
5 & 80 & 2.00 & 1.05 & 55.9 & 99.4 \\
6 & 80 & 2.00 & 2.00 & 65.0 & 98.8 \\
\hline
\end{tabular}

${ }^{\text {a }}$ Conversion of $\mathbf{1 1}$ after $1 \mathrm{~min}$ and $5 \mathrm{~min}$, respectively (determined by HPLC as free boronic acid) as organic base because the formed hydrochloride salt proved to be soluble in dioxane at elevated temperatures. The rate of $N$ acylation of $\mathbf{1 1}$ increases with higher temperature (Table 3, Entries 1-3) as well as a larger excess of valeryl chloride (Table 3, Entries 4-5). Using equimolar amounts of valeryl chloride and DIPEA further accelerates the reaction (Table 3, Entry 6), achieving almost full conversion after 5 min (98.8\%).

The final step of our targeted reaction cascade is the saponification of 5 to yield valsartan precursor $\mathbf{1 3}$ (Scheme 3, step 3). As a dioxane-water mixture was found to be optimal for the preceding Suzuki coupling step, ester hydrolysis of $\mathbf{5}$ was performed in the same solvents. At a temperature of $80^{\circ} \mathrm{C}$, the rate of methyl ester hydrolysis was found to increase with a larger molar excess of sodium hydroxide (Table 4, Entries 1-4). Substitution of the base by potassium hydroxide did not have a considerable impact on the conversion (Table 4, Entry 5). Raising the water content in the reaction solution to $55 \mathrm{v} \%$ slightly decelerated the conversion (Table 4, Entry 6) and a further increase to $60 \mathrm{v} \%$ caused solubility issues.

\section{Optimization of sequential steps 1 and 2 in batch}

For Pd-catalyzed Suzuki-Miyaura cross-couplings, the presence of a base is essential for the reaction to occur [35]. Hence, the $\mathrm{pH}$ of the reaction environment affects the rate of C-C bond formation [36]. In view of the performance of the Suzuki coupling subsequently to step 1, different influencing factors on the $\mathrm{pH}$ of the reaction mixture have to be considered. These include the formation of hydrogen chloride during the $\mathrm{N}$ acylation step and hydrolysis of the excess acid chloride to the corresponding carboxylic acid upon addition of water. Consequently, the $\mathrm{pH}$ of the reaction mixture after step 1 is acidic and part of potassium carbonate, which is added for the Suzuki coupling, gets neutralized. In order to study the effect of the $\mathrm{pH}$ on the Suzuki coupling step and to identify the necessary amount of potassium carbonate to be added, we performed steps 1 and 2 in a sequential fashion in one-pot (Scheme 4).

For the sequential performance of steps 1 and 2, $N$-acylation of 11 was accomplished using 2 mol eq. of both valeryl chloride and DIPEA in dioxane at $80^{\circ} \mathrm{C}$. Upon completion of 
Table 4 Optimization of reaction conditions of step 3 in batch

\begin{tabular}{lllll}
\hline Entry & Solvent & Base & $\begin{array}{l}\text { Mol eq. } \\
\text { base }\end{array}$ & $\begin{array}{l}\text { Conversion } \\
/ \%\end{array}$ \\
\hline 1 & Dioxane: $\mathrm{H}_{2} \mathrm{O}=1: 1$ & $\mathrm{NaOH}$ & 2.5 & 29.5 \\
2 & Dioxane: $\mathrm{H}_{2} \mathrm{O}=1: 1$ & $\mathrm{NaOH}$ & 5.0 & 46.1 \\
3 & Dioxane: $\mathrm{H}_{2} \mathrm{O}=1: 1$ & $\mathrm{NaOH}$ & 10.0 & 67.3 \\
4 & Dioxane: $\mathrm{H}_{2} \mathrm{O}=1: 1$ & $\mathrm{NaOH}$ & 20.0 & 81.3 \\
5 & Dioxane: $\mathrm{H}_{2} \mathrm{O}=1: 1$ & $\mathrm{KOH}$ & 10.0 & 67.7 \\
6 & Dioxane: $\mathrm{H}_{2} \mathrm{O}=45: 55$ & $\mathrm{NaOH}$ & 10.0 & 61.3 \\
\hline
\end{tabular}

${ }^{\text {a }}$ Conversion of 5 at $80^{\circ} \mathrm{C}$ after 5 min (determined by HPLC)

the reaction, the reaction mixture was quenched with an equal volume of water. Then, potassium carbonate, 2iodobenzonitrile 7c and Pd-catalyst $\mathrm{Ce}_{0.20} \mathrm{Sn}_{0.79} \mathrm{Pd}_{0.01} \mathrm{O}_{2-\delta}$ were added to the reaction flask in order to achieve formation of 5. We compared the Suzuki coupling step performed in one-pot with the optimized separate Suzuki coupling, exhibiting a $\mathrm{pH}$ of 11.3 in the presence of $1.5 \mathrm{~mol}$ eq. of potassium carbonate (Table 5, Entry 1). When the same amount of base was used in the one-pot experiment, a pH of only 9.7 was obtained and the conversion in the Suzuki coupling step was considerably lower (Table 5, Entry 2). Therefore, another $0.17 \mathrm{mmol}$ of $\mathrm{K}_{2} \mathrm{CO}_{3}$ were added, corresponding to the employed amount of valeryl chloride reagent in step 1. In doing so, the $\mathrm{pH}$ approaches the reference value and conversion was enhanced significantly (Table 5, Entry 3). Further increasing the amount of base in the reaction mixture gave comparable conversion (Table 5, Entry 4). Upon addition of $0.39 \mathrm{mmol}$ of base, formation of a second liquid phase was observed (Table 5, Entry 5), which was confirmed by following the reaction with the Crystalline (Technobis) [37]. The device is designed for studying crystallization processes by turbidity measurements but also allows real time monitoring of reactions via a particle view camera. Regarding obtained results and in view of the sequential performance of steps 1 and 2 in the multistep continuous setup for the synthesis of $\mathbf{1 3}$, the use of $3.7 \mathrm{~mol}$ eq. potassium carbonate in the Suzuki coupling step was considered as most appropriate.
Table 5 Effect of $\mathrm{K}_{2} \mathrm{CO}_{3}$ addition on $\mathrm{pH}$ and conversion of the Suzuki coupling step when performed after $N$-acylation in a one-pot fashion

\begin{tabular}{lllll}
\hline Entry & $\begin{array}{l}\mathrm{K}_{2} \mathrm{CO}_{3} \\
/ \mathrm{mmol}\end{array}$ & $\begin{array}{l}\mathrm{K}_{2} \mathrm{CO}_{3} \\
/ \text { mol eq. }\end{array}$ & $\mathrm{pH}^{\mathrm{b}}$ & $\begin{array}{l}\text { Conversion } \\
\text { Step 2 }\end{array}$ \\
\hline $1^{\mathrm{d}}$ & 0.11 & 1.5 & 11.3 & 97.7 \\
2 & 0.11 & 1.5 & 9.7 & 33.7 \\
3 & 0.28 & 3.7 & 10.9 & 82.4 \\
4 & 0.33 & 4.4 & 11.0 & 83.4 \\
5 & 0.39 & 5.2 & 11.1 & n.d. \\
\hline
\end{tabular}

n.d. $=$ not determined

${ }^{\mathrm{a}}$ Relative to $\mathbf{7 c}$

${ }^{\mathrm{b}} \mathrm{pH}$ determined with a Mettler Toledo FiveEasy ${ }^{\mathrm{TM}} \mathrm{pH}$ meter equipped with a Mettler Toledo LE409 probe after performance of step $1(55 \mathrm{mM}$ 11, 2 mol eq. valeryl chloride, $2 \mathrm{~mol}$ eq. DIPEA, $1.5 \mathrm{~mL}$ dioxane, $80^{\circ} \mathrm{C}$, $25 \mathrm{~min}$ ) and addition of $1.5 \mathrm{~mL} \mathrm{H}_{2} \mathrm{O}$ and $\mathrm{K}_{2} \mathrm{CO}_{3}$

${ }^{\mathrm{c}}$ Conversion of $\mathbf{7 c}$ after $30 \mathrm{~min}$ (determined by HPLC)

${ }^{\mathrm{d}}$ Optimized separate Suzuki coupling ( $25 \mathrm{mM}$ 7c, $1.1 \mathrm{~mol}$ eq. 12, 1.5 mol eq. $\mathrm{K}_{2} \mathrm{CO}_{3}, 3 \mathrm{~mL}$ dioxane: $\left.\mathrm{H}_{2} \mathrm{O}=1: 1\right)$

${ }^{\mathrm{e}}$ Formation of two liquid phases (monitored via Crystalline, Technobis)

\section{Continuous setups for the individual steps}

After optimization of the individual steps in batch, we first targeted the realization of $\mathrm{N}$-acylation as well as saponification in continuous flow. As both transformations exhibit a monophasic reaction solution, we decided to utilize a stainless steel coil (L x O.D. x I.D. $3.0 \mathrm{~m} \times 1 / 16$ in. $\times 0.030$ in., $V=$ $1.368 \mathrm{~mL}$ ) as reactor in combination with a split-andrecombine unit $(\mathrm{V}=0.565 \mathrm{~mL})$ as static mixer (Scheme 5). The mixing efficiency of the latter and its applicability for rapid chemical transformations has been demonstrated lately for the aerobic oxidation of Grignard reagents in continuous flow [38]. The reactor comprises a precooling section, after which the two reagent streams are merged and introduced into a split-and-recombine section for enhanced mixing.

Regarding the continuous performance of steps 1 and 3, a dual syringe infusion pump (LA-120, Landgraf) was utilized for steady reagent delivery into the reactor setup $(\mathrm{V}=$ $1.933 \mathrm{~mL}$ ), which was assembled using standard HPLC

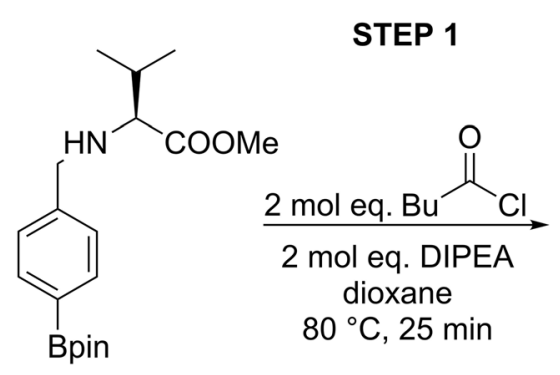

11

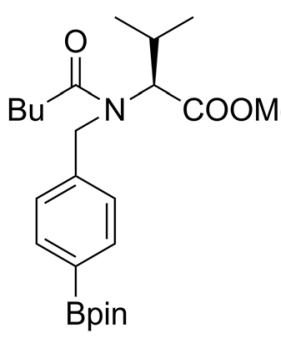

12
STEP 2

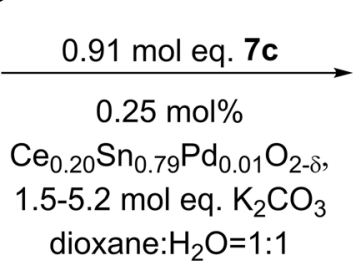

$80^{\circ} \mathrm{C}, 1 \mathrm{~h}$

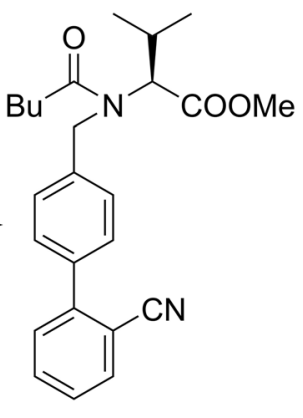

5

Scheme 4 Steps 1 and 2 sequentially performed in one-pot fashion in batch 
Scheme 5 Continuous setup for (a) $\mathrm{N}$-acylation as well as (b) methyl ester hydrolysis using a coil reactor at ambient pressure ( $\mathrm{S}=$ syringe pump, $\mathrm{M}=$ split-andrecombine reactor as static mixer)

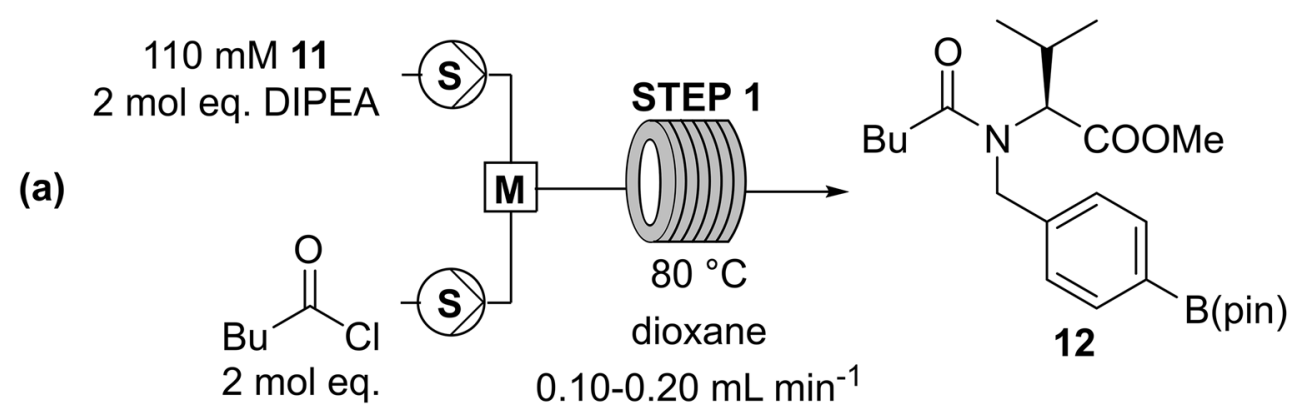

(b)

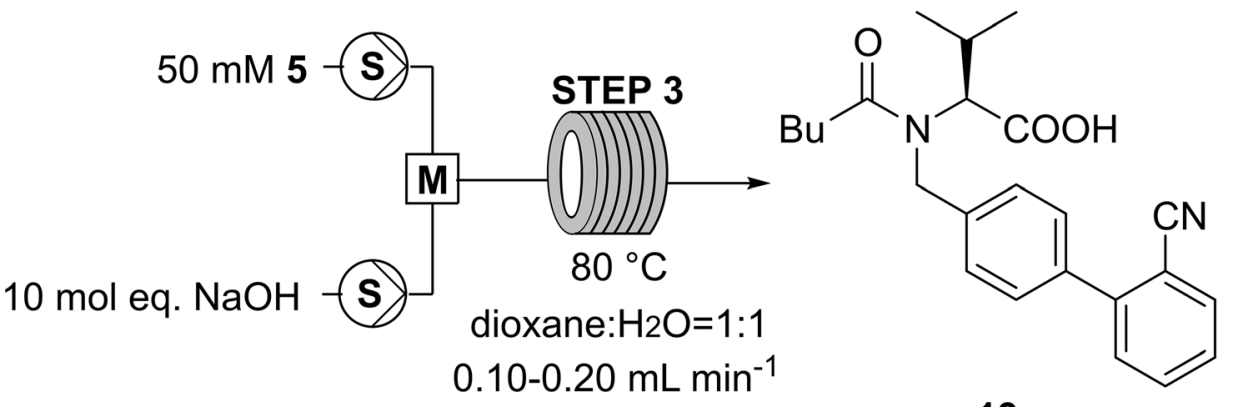

13 fittings. The performance of the continuous setup at ambient pressure was determined at three different total flow rates based on the conversion of $\mathbf{1 1}$ and $\mathbf{5}$, respectively (for details see Supporting Information). In both cases, substrate conversion of $>99 \%$ was obtained at the lowest flow rate of $0.10 \mathrm{~mL} \mathrm{~min}^{-1}$, which corresponds to a calculated residence time of $\tau \sim 19 \min$ (Table 6 , Entry 1 ). Whereas the $N$-acylation step proved to be similarly efficient at higher flow rates of 0.15 and $0.20 \mathrm{~mL} \mathrm{~min}{ }^{-1}$, for methyl ester hydrolysis conversion decreased noticeably (Table 6, Entries 2-3). However, the observed general trend of higher conversion at lower flow rates suggests that the mixing obtained with the split-andrecombine reactor is sufficient for both transformations.

Next, we focused on the continuous setup for the second step of our cascade towards 13, Suzuki-Miyaura cross-coupling. The applicability of our heterogeneous Pd-catalyst for the continuous Suzuki coupling of various substituted bromoarenes with phenylboronic utilizing the Plug \& Play reactor has already been reported by our group [29, 30]. Therefore, we decided to adopt this approach for the $\mathrm{C}-\mathrm{C}$

Table 6 Conversion of step 1 and step 3 when performed in continuous flow using different flow rates

\begin{tabular}{|c|c|c|c|c|c|}
\hline Entry & $\begin{array}{l}\text { V(reactor) } \\
/ \mathrm{mL}\end{array}$ & 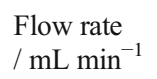 & $\begin{array}{l}\tau^{\mathrm{a}} \\
/ \min \end{array}$ & $\begin{array}{l}\text { Conversion } \\
\text { Step } 1^{b} / \%\end{array}$ & $\begin{array}{l}\text { Conversion } \\
\text { Step } 3^{\mathrm{c}} / \%\end{array}$ \\
\hline 1 & 1.93 & 0.10 & 19.3 & 99.9 & 99.5 \\
\hline 2 & 1.93 & 0.15 & 12.9 & 99.7 & 97.2 \\
\hline 3 & 1.93 & 0.20 & 9.7 & 99.6 & 92.6 \\
\hline
\end{tabular}

${ }^{\mathrm{a}}$ Calculated residence time

${ }^{\mathrm{b}}$ Conversion of $\mathbf{1 1}$ after $2.5 \tau$ (determined by HPLC)

${ }^{\mathrm{c}}$ Conversion of $7 \mathbf{c}$ after $2.5 \tau$ (determined by HPLC) cross-coupling of boronic acid ester $\mathbf{1 2}$ with aryl halide $\mathbf{7 c}$. In view of the performance of our three-step reaction cascade, we based the experiment design on the preceding $N$-acylation step. For step 1 quantitative conversion of $\mathbf{1 1}$ is targeted, which is achieved in dioxane using a flow rate of $0.10 \mathrm{~mL} \mathrm{~min}^{-1}$. As we identified an equivolume dioxanewater mixture as optimal for subsequent Suzuki coupling, we intended to merge the reagent stream of step 1 with an aqueous stream of the same flow rate. Consequently, for testing step 2 separately in a continuous fashion, we chose a flow rate of $0.20 \mathrm{~mL} \mathrm{~min}^{-1}$. In the experiment, a pre-mixed reagent solution containing both coupling partners as well as potassium carbonate was pumped through the Plug \& Play reactor [30], which was equipped with an HPLC column (L x I. D. $120 \times 8 \mathrm{~mm}$ ) filled with catalyst particles $(4.7 \mathrm{~g}$ ) (Scheme 6, for details see Supporting Information). Due to the backpressure of the catalyst bed (2-3 bar) and incompatibility of the solvent mixture with the available HPLC pump, a highpressure syringe pump (VIT-FIT HP, LAMBDA Instruments) in combination with stainless steel syringes was utilized. At the chosen flow rate of $0.2 \mathrm{~mL} \mathrm{~min}^{-1}$, the mean residence time inside the HPLC column containing the catalytic species was determined by measurement of a tracer-determined residence time distribution curve to be $22.3 \mathrm{~min}$. Utilizing the abovementioned setup, step 2 of the targeted reaction cascade was successfully performed in a continuous fashion. After an initial equilibration phase of $50 \mathrm{~min}$ (consuming $10 \mathrm{~mL}$ of stock solution), the target compound $\mathbf{5}$ was obtained with an average $95 \%$ yield (Fig. 1).

Regarding the performance of Suzuki cross-coupling reactions in continuous flow, leaching of catalytically active $\mathrm{Pd}$ species from the solid support into the reaction solution is known to be a major issue $[39,40]$. Therefore, the contents 
Scheme 6 Continuous setup for the Suzuki coupling utilizing the Plug \& Play reactor equipped with an HPLC column filled with particles of $\mathrm{Ce}_{0.20} \mathrm{Sn}_{0.79} \mathrm{Pd}_{0.01} \mathrm{O}_{2-\delta}$ $\left(\mathrm{S}_{\mathrm{P}}=\right.$ high-pressure syringe pump)

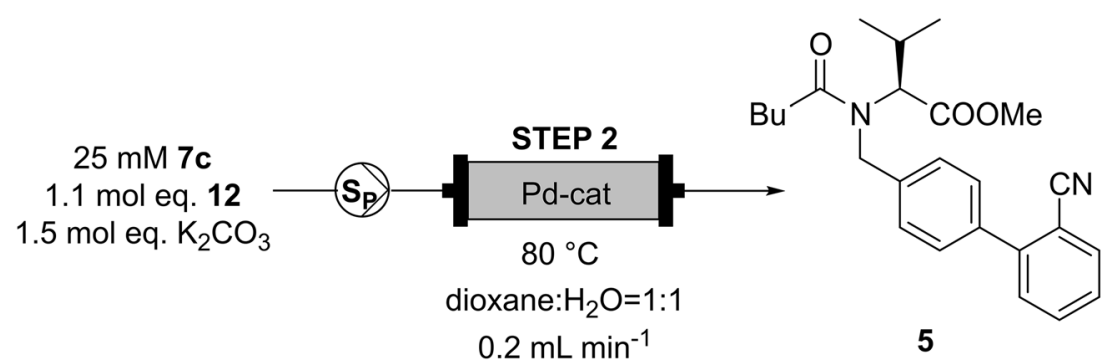

of palladium, cerium and tin in the outlet flow of the continuous experiment were measured by ICP-MS after certain time points (Table 7). As already observed in the batch experiments, the amount of tin in the reaction solution was found to be negligible in all samples $\left(<0.02 \mathrm{mg} \mathrm{kg}^{-1}\right)$. The concentration of cerium in the outlet flow instead was determined to decrease over the course of the continuous experiment and was quantified to be $0.70 \mathrm{mg} \mathrm{kg}^{-1}$ after $4 \mathrm{~h}$. As already reported previously [29], the heterogeneous catalysts with the molecular formula $\mathrm{Ce}_{0.99-\mathrm{x}} \mathrm{Sn}_{\mathrm{x}} \mathrm{Pd}_{0.01} \mathrm{O}_{2-\delta}$ show a significant loss of palladium during the initial phase $(0-120 \mathrm{~min})$ of the Suzuki cross-coupling in continuous flow (literature conditions: $1.10 \mathrm{~g}$ of Pd-catalyst, flow rate $0.45 \mathrm{~mL} \mathrm{~min}^{-1}$ ). However, after equilibration of the system the palladium content drops below the limit of quantification [29]. Likewise, considerable leaching of palladium into the reaction solution was also observed in the continuous Suzuki coupling step for the synthesis of valsartan precursor $\mathbf{5}$ over the entire runtime of the experiment. Presumably, due to the lower flow rate of $0.2 \mathrm{~mL} \mathrm{~min}^{-1}$ and the larger amount of catalyst compared to mentioned literature experiment [29], the applied system has not reached its steady-state within the duration of the experiment, which was limited by the availability of boronic acid ester 12. However, in view of a possible application of the reaction setup for continuous Suzuki coupling on a larger scale, the implementation of a palladium scavenging strategy is advisable. Galaffu et al. reported the successful use of different sulfur-based silica scavengers for the removal of palladium from a variety of advanced synthetic intermediates including valsartan precursor 5 [19]. In their study, after the Suzuki coupling step $\left(1 \mathrm{~mol} \% \mathrm{Pd}\left(\mathrm{PPh}_{3}\right)_{4}, \mathrm{DME} / \mathrm{EtOH} / \mathrm{H}_{2} \mathrm{O}\right.$, $\mathrm{Na}_{2} \mathrm{CO}_{3}$ ) the residual amount of palladium in product 5 was effectively decreased from $2100 \mathrm{ppm}$ to $<1 \mathrm{ppm}$ by the utilization of respective functionalized silica frameworks [19].

\section{Multistep continuous setup for the synthesis of 13}

After confirming the feasibility of the three single steps of the reaction cascade in continuous flow, an integrated setup for their consecutive performance was developed by simple combination of the individual reaction modules (Scheme 7). The $N$-acylation step was performed in the coil reactor setup already described using a flow rate of $0.10 \mathrm{~mL} \mathrm{~min}{ }^{-1}$ by means of high-pressure syringe pumps (VIT-FIT HP, Lambda Instruments). The outlet stream was then quenched with an aqueous potassium carbonate solution delivered by an HPLC pump

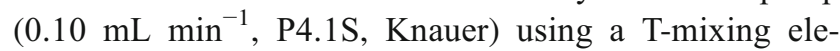
ment. For the key step of the reaction cascade, SuzukiMiyaura cross-coupling, the reaction solution was introduced at resulting $0.20 \mathrm{~mL} \mathrm{~min}^{-1}$ into the Plug \& Play reactor [30] equipped with a fixed-bed of heterogeneous Pd-catalyst $\mathrm{Ce}_{0.20} \mathrm{Sn}_{0.79} \mathrm{Pd}_{0.01} \mathrm{O}_{2-\delta}$. Finally, the process stream was merged with a sodium hydroxide solution supplied by a syringe pump $\left(0.1 \mathrm{~mL} \min ^{-1}\right.$, LA-120, Landgraf) to achieve methyl ester hydrolysis. For this step, a longer reactor coil (PTFE, L x O.D. $x$ I.D. $10.0 \mathrm{~m} \times 1 / 16$ in. $\times 0.031$ in.) was chosen in
Fig. 1 Conversion of $7 \mathbf{c}$ and yield of 5 in continuous SuzukiMiyaura cross-coupling utilizing the Plug \& Play reactor

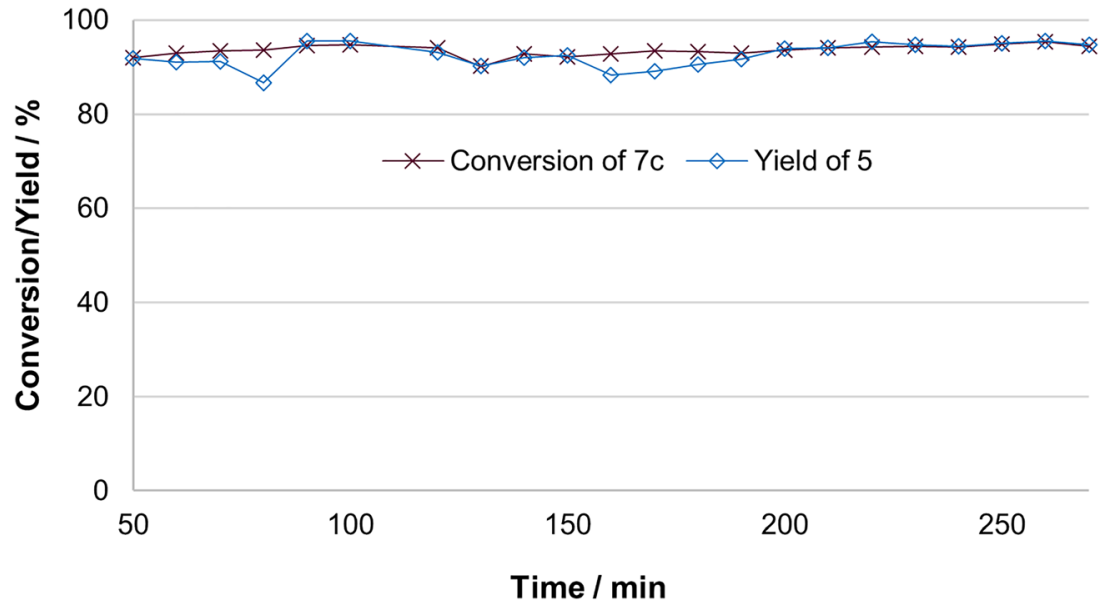


Table 7 Leaching of $\mathrm{Pd}, \mathrm{Ce}$ and $\mathrm{Sn}$ into the reaction solution in the continuous Suzuki coupling determined by ICP-MS

\begin{tabular}{lllll}
\hline Entry & $\begin{array}{l}\text { Time } \\
/ \mathrm{min}\end{array}$ & $\begin{array}{l}\mathrm{Ce} \\
/ \mathrm{mg} \mathrm{kg}^{-1}\end{array}$ & $\begin{array}{l}\mathrm{Sn} \\
/ \mathrm{mg} \mathrm{kg}^{-1}\end{array}$ & $\begin{array}{l}\mathrm{Pd} \\
/ \mathrm{mg} \mathrm{kg}^{-1}\end{array}$ \\
\hline 1 & $50-60$ & $4.1 \pm 0.2$ & $<0.02$ & $31.6 \pm 0.6$ \\
2 & $120-130$ & $10 \pm 1$ & $<0.02$ & $84.2 \pm 0.8$ \\
3 & $170-180$ & $2.7 \pm 0.2$ & $<0.02$ & $189 \pm 1$ \\
4 & $230-240$ & $0.70 \pm 0.02$ & $<0.02$ & $207 \pm 4$ \\
\hline
\end{tabular}

comparison to the individual setup in order to compensate for the higher flow rate of $0.3 \mathrm{~mL} \mathrm{~min}{ }^{-1}$ and to achieve a similar residence time. With this setup exhibiting an estimated total residence time of roughly $1 \mathrm{~h}$, the three steps of the reaction cascade were successfully performed continuously in a consecutive fashion for over $6 \mathrm{~h}$. After an initial equilibration phase (260 $\mathrm{min}$ ), quantitative conversion of 2-iodobenzonitrile 7c was achieved and the target compound 13 was obtained with up to $96 \%$ yield $(90 \pm 4 \%$ yield, values fluctuating around the mean) and $73 \%$ enantiomeric excess (determined by achiral and chiral HPLC, respectively; see Supporting Information). Performing the analogous three-step reaction sequence from $\mathbf{1 1}$ to $\mathbf{1 3}$ in batch including purification of intermediates 5 and 12, the obtained overall yield was only $28 \%$ (see Supporting Information for the performance of the individual steps in batch). Therefore, translation of the multistep cascade from batch to continuous flow allowed a significant increase in yield of valsartan precursor 13. Addressing the moderate enantiopurity of compound $\mathbf{1 3}$ synthesized in continuous flow, racemization apparently occurred during the saponification step as intermediates $\mathbf{5}$ and $\mathbf{1 2}$ were shown to be enantiopure (see Supporting information for determination of enantiopurity of $\mathbf{5}$ and 12). Consequently, in view of a potential application of the developed continuous approach for actual API production, further process optimization is required to achieve the synthesis of an enantiomerically pure compound.

Regarding the selectivity of the reaction steps, in $\mathrm{Ce}_{0.99-}$ ${ }_{x} \mathrm{Sn}_{\mathrm{x}} \mathrm{Pd}_{0.01} \mathrm{O}_{2-\delta}$ catalyzed Suzuki cross-coupling oxidation and homocoupling of the boronic acid species were reported to cause minor side product formation upon depletion of the aryl halide coupling partner [27]. Therefore, only a slight excess of 1.10 mol eq. of boronic acid ester $\mathbf{1 2}$ was employed to minimize formation of the respective by-products, which were presumably present in the reaction mixture and can be removed by chromatographic techniques. Apart from that, $N$-acylation as well as methyl ester hydrolysis proved to be rather clean reaction steps. This is supported by the fact that HPLC analysis of the outlet flow of the thee-step continuous process revealed side products to the extent of 9 area $\%$ compared to the product peak $(\lambda=230 \mathrm{~nm})$, which most likely originate from the $10 \%$ excess of $\mathbf{1 2}$.

\section{Conclusion}

In conclusion, we developed an approach for the integrated multistep synthesis of a late-stage precursor of the active pharmaceutical ingredient valsartan using a modular continuous setup composed of two coil reactor units and a fixed-bed reactor. After equilibration of the multistep setup, it was demonstrated to successfully yield the target compound $\mathbf{1 3}$ with up to $96 \%$ yield with a moderate ee. Whereas in published approaches for the continuous synthesis of a valsartan precursor in a packed-bed reactor little functionalized biphenyls were obtained [21, 22], with our described setup we were able to perform the synthesis of a more advanced valsartan precursor, in this way highlighting the broad functional-group tolerance of the employed heterogeneous palladium catalyst. However, leaching of palladium into the reaction solution was observed for the

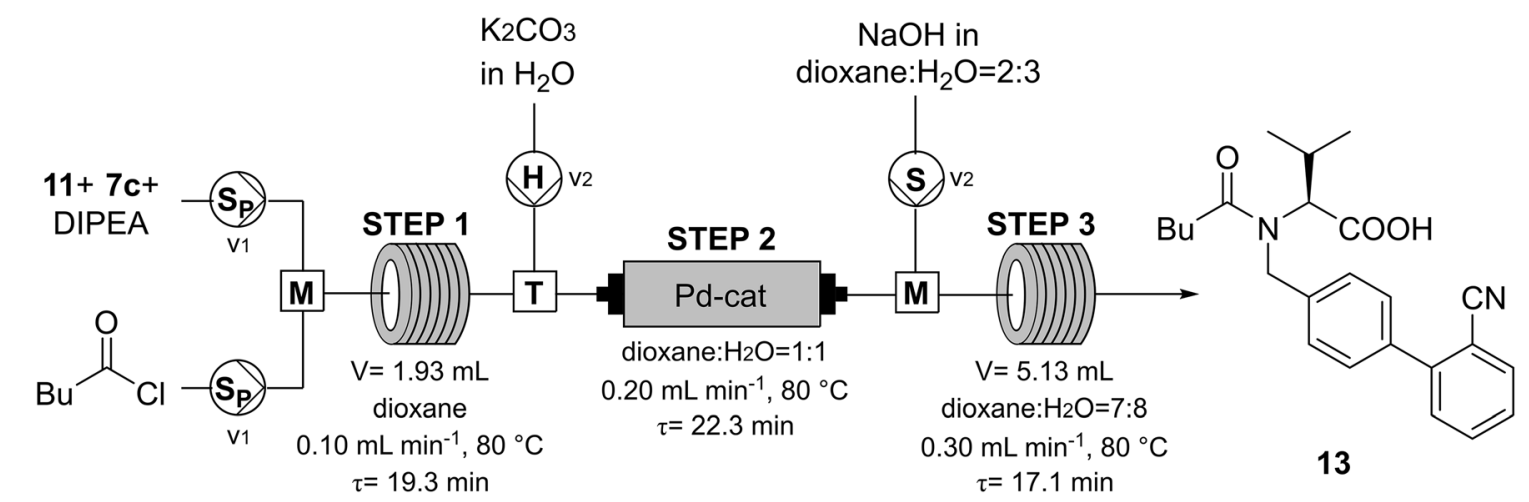

Scheme 7 Three-step continuous setup for the synthesis of valsartan precursor $\mathbf{1 3}$ ( $\mathrm{S}_{\mathrm{P}}=$ high-pressure syringe pump, $\mathrm{S}=$ syringe pump, $\mathrm{H}=\mathrm{HPLC}$ pump, $\mathrm{M}=$ split-and-recombine reactor, $\mathrm{T}=\mathrm{T}$-mixer, $\mathrm{v}_{1}=0.05 \mathrm{~mL} \mathrm{~min}^{-1}, \mathrm{v}_{2}=0.10 \mathrm{~mL} \mathrm{~min}^{-1}$ ) 
heterogeneous catalyst employed in the Suzuki-Miyaura cross-coupling step. Hence, there is room for improvement of the process, for example by implementation of a Pd scavenger or by utilization of a more leachingresistant Pd catalyst. Nevertheless, with the development of the three-step continuous setup, the applicability of continuous flow techniques for the synthesis of advanced chemical intermediates has been proven once more and hopefully encourages research in this field.

\section{Experimental section}

\section{General information}

Chemicals and solvents were purchased from commercial suppliers and used as received [Ark Pharm: 2-(4-(bromomethyl)phenyl)-4,4,5,5-tetramethyl-1,3,2dioxaborolane (97\%); Fluorochem: L-valine methyl ester hydrochloride (99\%), 2-iodobenzonitrile (98\%); Sigma Aldrich: potassium carbonate (99\%), valeryl chloride (98\%), anisole (99\%); Carl Roth: dioxane $(>99.5 \%), \mathrm{NaOH}(>99 \%)]$. Analytical thin layer chromatography was performed on pre-coated aluminium plates (Merck, silica gel $60, \mathrm{~F}_{254}$ ) and spots were visualized with UV light $(254 \mathrm{~nm})$ and potassium permanganate stain. Column chromatography purifications were carried out using MN silica gel 60 (70-230 mesh). For monitoring of the reaction progress and determination of enantiomeric excess, an Agilent 1100 series HPLC system was utilized (for HPLC parameters see Supporting Information). HPLC-MS measurements were performed on a Waters Acquity H-Class system equipped with a Waters Acquity SQD detector. For ICP-MS measurements, an Agilent 7700x ICP-MS system was employed after microwave assisted acidic digestion of the samples. Measurement of the $\mathrm{pH}$ was achieved using a Mettler Toledo FiveEasy ${ }^{\mathrm{TM}} \mathrm{pH}$ bench meter equipped with a Mettler Toledo LE409 probe. NMR-measurements were recorded using a Bruker Avance III $300 \mathrm{MHz}$ spectrometer $\left({ }^{1} \mathrm{H}\right.$ : $300 \mathrm{MHz},{ }^{13} \mathrm{C}: 75 \mathrm{MHz}$, for NMR-data see Supporting Information).

\section{Batch experiments for optimization of step 1}

In a typical $N$-acylation experiment, borate $\mathbf{1 1}$ (82.5 $\mu \mathrm{mol}, 55 \mathrm{mM})$, DIPEA (1.05-2.00 mol eq.) and anisole $(133 \mathrm{mM}$, internal standard) were dissolved in dioxane to achieve a total volume of $1.5 \mathrm{~mL}$. To start the reaction, valeryl chloride (1.05-2.00 mol eq.) was added at room temperature and the reaction was kept stirring $(2000 \mathrm{rpm})$ with a magnetic stirrer at elevated temperature $\left(40-80{ }^{\circ} \mathrm{C}\right)$ for $20 \mathrm{~min}$. To examine the reaction progress, an aliquot $(20 \mu \mathrm{L})$ was withdrawn from the reaction solution, quenched with $\mathrm{MeOH}: \mathrm{H}_{3} \mathrm{PO}_{4}=50: 50$ $(400 \mu \mathrm{L})$ and analyzed by HPLC (Method A, see Supporting Information for details).

\section{Batch experiments for optimization of step 2}

For optimization of Suzuki-Miyaura cross-coupling reaction, 2halobenzonitrile $\mathbf{7 b - c}(75 \mu \mathrm{mol}-150 \mu \mathrm{mol}, 25 \mathrm{mM})$, borate $\mathbf{1 2}$ (1.1-1.5 mol eq.), $\mathrm{K}_{2} \mathrm{CO}_{3}$ (1.5 mol eq.) and anisole $(67 \mathrm{mM}$, internal standard) were dissolved in the respective reaction solvent to achieve a total volume of 3-6 $\mathrm{mL}$. Then, $\mathrm{Ce}_{0.99}$ ${ }_{\mathrm{x}} \mathrm{Sn}_{\mathrm{x}} \mathrm{Pd}_{0.01} \mathrm{O}_{2-\delta}$ (2.1-21.4 mg, corresponding to $0.05-1 \mathrm{~mol} \%$ $\mathrm{Pd})$ was added and the reaction mixture was stirred (2000 rpm) at elevated temperature $\left(65-85{ }^{\circ} \mathrm{C}\right)$ for $90-120 \mathrm{~min}$. For investigation of the reaction progress, an aliquot $(40 \mu \mathrm{L})$ was withdrawn from the reaction solution, quenched with $\mathrm{MeOH}: \mathrm{H}_{3} \mathrm{PO}_{4}$ buffer $=55: 45(400 \mu \mathrm{L})$ and analyzed by HPLC (Method B for reactions with $\mathbf{7 c}$, method $C$ for reactions with $\mathbf{7 b}$, see Supporting Information for details). For determination of leaching of $\mathrm{Pd}, \mathrm{Ce}$ and $\mathrm{Sn}$, the reaction solution was filtered, the filter washed with the reaction solvent and the solvent was evaporated. Obtained solid residue was then analyzed by ICPMS after microwave assisted acidic digestion of the samples.

\section{Batch experiments for optimization of step 3}

In a typical methyl ester hydrolysis experiment, biphenyl compound $5(60 \mu \mathrm{mol}, 20 \mathrm{mM})$ and anisole $(67 \mathrm{mM}$, internal standard) were dissolved in the respective reaction solvent to achieve a total volume of $2.95 \mathrm{~mL}$. To initiate the reaction, aqueous base $(\mathrm{NaOH}$ or $\mathrm{KOH}, 50 \mu \mathrm{L}, 2.5-20$ mol eq.) was added and the reaction mixture was stirred $(2000 \mathrm{rpm})$ at $80^{\circ} \mathrm{C}$ for $30 \mathrm{~min}$. To monitor the reaction progress, an aliquot $(40 \mu \mathrm{L})$ was quenched with $\mathrm{MeOH}: \mathrm{H}_{3} \mathrm{PO}_{4}$ buffer $=55: 45$ $(400 \mu \mathrm{L})$ and analyzed by HPLC (Method B, see Supporting Information for details).

\section{Batch experiments for optimization of sequential steps 1 and 2}

For optimization of the sequential performance of steps 1 and 2 in batch, borate $11(82.5 \mu \mathrm{mol}, 55 \mathrm{mM})$, DIPEA (2.00 mol eq.) and anisole (185 mM, internal standard) were dissolved in dioxane to achieve a total volume of $1.5 \mathrm{~mL}$. To start the reaction, valeryl chloride ( $2.00 \mathrm{~mol}$ eq.) was added at room temperature and the reaction was kept stirring $(2000 \mathrm{rpm})$ at $80{ }^{\circ} \mathrm{C}$. After $20 \mathrm{~min}$ of reaction, deionized water $(1.5 \mathrm{~mL})$, potassium carbonate $(0.11-0.50 \mathrm{mmol})$ and 2-iodobenzonitrile $7 \mathbf{c}(75 \mu \mathrm{mol})$ were added to the reaction solution. Then $\mathrm{Ce}_{0.20} \mathrm{Sn}_{0.79} \mathrm{Pd}_{0.01} \mathrm{O}_{2-\delta}$ ( $2.7 \mathrm{mg}$, corresponding to $0.25 \mathrm{~mol} \% \mathrm{Pd}$ ) was added and the reaction mixture was stirred $(2000 \mathrm{rpm})$ at $80^{\circ} \mathrm{C}$ for $60 \mathrm{~min}$. For investigation of the reaction progress, an aliquot $(40 \mu \mathrm{L})$ was 
withdrawn from the reaction solution, quenched with $\mathrm{MeOH}: \mathrm{H}_{3} \mathrm{PO}_{4}$ buffer $=55: 45(400 \mu \mathrm{L})$ and analyzed by HPLC (Method B, see Supporting Information for details).

\section{Integrated synthesis of $\mathbf{1 3}$ in continuous flow}

Solution A [boronic acid ester 11 (110 mM, 1.1 mol eq.), 2iodobenzonitrile 7c $(100 \mathrm{mM})$, DIPEA $(220 \mathrm{mM}$, 2.2 mol eq.), anisole $(240 \mathrm{mM})$ as internal standard] and solution B [valeryl chloride (220 mM, $2.2 \mathrm{~mol}$ eq.)] were prepared in dioxane and degassed in an ultrasonic bath for $15 \mathrm{~min}$. After equilibration of the reactor system, the two reagent solutions were introduced into the first part of the reactor for $N$-acylation (step 1, split-and-recombine reactor $+3 \mathrm{~m}$ PEEK coil $\mathrm{L} \times$ O.D. $x$ I.D. $10.0 \mathrm{~m} \times 1 / 16$ in. $\times$ 0.030 in., $V_{\text {total }}=1.93 \mathrm{~mL}, \tau=19.3 \mathrm{~min}$ ) by means of highpressure syringe pumps (VIT-FIT HP, Lambda Instruments) at $80{ }^{\circ} \mathrm{C}$ using a flow rate of $0.05 \mathrm{~mL} \mathrm{~min}^{-1}$ (resulting in a total flow rate of $0.1 \mathrm{~mL} \mathrm{~min}^{-1}$ for step 1). The outlet stream was quenched with an aqueous solution of potassium carbonate (185 mM, 3.7 mol eq.) delivered by an HPLC pump (P4.1S, Knauer) with a flow rate of $0.1 \mathrm{~mL} \mathrm{~min}^{-1}$ using a T-mixing element. The resulting reaction solution was then pumped through the Plug \& Play reactor [30] equipped with a preparative HPLC column (L x I.D. $120 \times 8 \mathrm{~mm}$ ) filled with Pdcatalyst $\mathrm{Ce}_{0.20} \mathrm{Sn}_{0.79} \mathrm{Pd}_{0.01} \mathrm{O}_{2-\delta}(4.3 \mathrm{~g})$ for Suzuki-Miyaura cross-coupling $(\tau=22.3 \mathrm{~min})$. Subsequently, the process stream was merged with a sodium hydroxide solution $\left(750 \mathrm{mM}, 15 \mathrm{~mol}\right.$ eq., dioxane: $\mathrm{H}_{2} \mathrm{O}=2: 3$ ) with a flow rate of $0.1 \mathrm{~mL} \mathrm{~min}^{-1}$ delivered by a syringe pump (LA-120, Landgraf) and introduced into the final part of the reactor to achieve methyl ester hydrolysis (step 3, split-and-recombine reactor $+10 \mathrm{~m}$ PEEK coil L $x$ O.D. $x$ I.D. $10.0 \mathrm{~m} \times 1 / 16 \mathrm{in} . \times$ 0.030 in., $V_{\text {total }}=5.13 \mathrm{~mL}, \tau=17.1 \mathrm{~min}$ ) to obtain targeted valsartan precursor 13. After certain time points, an aliquot of the outlet flow $(50 \mu \mathrm{L})$ was quenched with $\mathrm{MeOH}: \mathrm{H}_{3} \mathrm{PO}_{4}=$ 55:45 $(400 \mu \mathrm{L})$ and analyzed by HPLC (Method B).

Acknowledgments Open access funding provided by Graz University of Technology. The authors kindly acknowledge the funding by the H2020FETOPEN-2016-2017 program of the European Commission (Grant agreement number: 737266-ONE FLOW).

\section{Compliance with ethical standards}

Conflict of interest On behalf of all authors, the corresponding author states that there is no conflict of interest.

Open Access This article is distributed under the terms of the Creative Commons Attribution 4.0 International License (http:// creativecommons.org/licenses/by/4.0/), which permits unrestricted use, distribution, and reproduction in any medium, provided you give appropriate credit to the original author(s) and the source, provide a link to the Creative Commons license, and indicate if changes were made.

\section{References}

1. Cardiovascular diseases (2017) World Health Organization. http:// www.who.int/news-room/fact-sheets/detail/cardiovasculardiseases-(cvds). Accessed 4 Sept 2018

2. Oparil S, Schmieder RE (2015). Circ Res 116:1074-1095

3. Goossen LJ, Melzer B (2007). J Org Chem 72:7473-7476

4. Kloss F, Neuwirth T, Haensch VG, Hertweck C (2018). Angew Chem Int Ed Engl 57:14476-14481

5. Siddiqui N, Husain A, Chaudhry L, Alam MS, Mitra M, Bhasi PS (2011). J Appl Pharm Sci 01:12-19

6. Li JJ, Corey EJ (2013) Drug discovery: practices, processes, and perspectives. Wiley-VCH, New Jersey

7. Davis J, Oparil S (2018). Curr Hypertens Rep 20:90

8. Vilela-Martin JF (2016). Drug Des, Dev Ther 10:1627-1639

9. Bühlmayer P, Ostermayer F, Schmidlin T (1991) Acyl compounds. Eur Patent EP 1991-810098, Aug 28, 1991; (1992) Chem Abstr 116:151772

10. Lamberth C, Dinges J (2016) Bioactive Carboxylic Compound Classes. Wiley-VCH, New Jersey; Chapter 7, p 91

11. Verardo G, Geatti P, Castaldi G, Toniutti N, Allegrini P (2005) A process for the preparation of valsartan and intermediates thereof. Eur patent application EP 1533305 A1, mar 25, 2005; (2005). Chem Abstr 142:482034

12. Sedelmeier G (2013) Process for the preparation of tetrazole derivatives from organo boron and organo aluminium azides. US patent US 8,569,528 B2, Oct 29, 2013; (2016). Chem Abstr 166:362689

13. Villa M, Allegrini P, Arrighi K, Paiocchi M (2001) Orthometalation process for the synthesis of 2-substituted-1-(tetrazol-5yl)benzenes. US patent US 6,271,375 B1, Aug 7, 2001; (1999). Chem Abstr 130:125215

14. Zhang CX, Zheng GJ, Bi FQ, Li YL (2008). Chin Chem Lett 19: 759-761

15. Zhang C, Zheng G, Fang L, Li Y (2006). Synlett 03:475-477

16. Tsiperman E, Fine S, Yurkovsky S, Braude V (2007) Process for preparing valsartan. PCT Int Appl WO 2007/005967 A2, Jan 11, 2007; (2007). Chem Abstr 146:122299

17. Seki M, Nagahama M (2011). J Org Chem 76:10198-10206

18. Ghosh S, Kumar AS, Mehta GN (2010). Beilstein J Org Chem 6:4-7

19. Galaffu N, Man SP, Wilkes RD, Wilson JRH (2007). Org Process Res Dev 11:406-413

20. Bessa Belmunt J, Huguet Clotet J, Perez Andres JA, Dalmases Barjoan P (2005) Process for the preparation of valsartan and precursors thereof. PCT Int Appl WO 2005/102987 A1, Nov 3, 2005; (2005). Chem Abstr 143:406147

21. Pandarus V, Gingras G, Béland F, Ciriminna R, Pagliaro M (2014). Org Process Res Dev 18:1550-1555

22. Nagaki A, Hirose $\mathrm{K}$, Tonomura $\mathrm{O}$, Taniguchi $\mathrm{S}$, Taga $\mathrm{T}$, Hasebe $\mathrm{S}$, Ishizuka N, Yoshida J-i (2016). Org Process Res Dev 20:687-691

23. Newman SG, Jensen KF (2013). Green Chem 15:1456-1472

24. FDA perspective on continuous manufacturing (2012) US food and drug Administation. https://www.fda.gov/downloads/AboutFDA/ CentersOffices/OfficeofMedicalProductsandTobacco/CDER/ UCM341197.pdf. Accessed 21 Jan 2019

25. Statement from FDA (2018) US Food and Drug Administration. https://www.fda.gov/News Events/Newsroom/ PressAnnouncements/ucm619024.htm. Accessed 30 Oct 2018

26. ONE-FLOW Research Project Home Page. https://one-flow.org. Accessed 20 Feb 2019

27. Lichtenegger GJ, Maier M, Hack1 M, Khinast JG, Gössler W, Griesser T, Kumar VSP, Gruber-Woelfler H, Deshpande PA (2017). J Mol Catal A Chem 426:39-51

28. Roh J, Vávrová K, Hrabálek A (2012). Eur J Org Chem 2012: $6101-6118$ 
29. Lichtenegger GJ, Maier M, Khinast JG, Gruber-Wölfler H (2016). J Flow Chem 6:244-251

30. Lichtenegger GJ, Tursic V, Kitzler H, Obermaier K, Khinast JG, Gruber-Wölfler H (2016). Chem Ing Tech 88:1518-1523

31. Huang F, Yip H-L, Cao Y (2016) Polymer photovoltaics: materials, physics, and dsevice engineering. Royal Society of Chemistry, Cambridge

32. Smith MD, Stepan AF, Ramarao C, Brennan PE, Ley SV (2003). Chem Commun 3:2652-2653

33. Smith MD, Mostofian B, Petridis L, Cheng X, Smith JC (2016). J Phys Chem B 120:740-747

34. Duefert MA, Billingsley KL, Buchwald SL (2013). J Am Chem Soc 135:12877-12885

35. Suzuki A (2002). J Organomet Chem 653:83-90

36. Hoffmann I, Blumenröder B, Onodi neé Thumann S, Dommer S, Schatz J (2015). Green Chem 17:3844-3857
37. Technobis Crystallization Systems Homepage. https://www. crystallizationsystems.com/Crystalline. Accessed 8 May 2019

38. Maier MC, Lebl R, Sulzer P, Lechner J, Mayr T, Zadravec M, Slama E, Pfanner S, Schmölzer C, Pöchlauer P, Kappe CO, Gruber-Woelfler H (2019). React Chem Eng 4:393-401

39. Bourouina A, Meille V, de Bellefon C (2018). J Flow Chem 8:117-121

40. Barreiro EM, Hao Z, Adrio LA, van Ommen JR, Hellgardt K, Hii KK (2018). Catal Today 308:64-70

Publisher's note Springer Nature remains neutral with regard to jurisdictional claims in published maps and institutional affiliations. 